DESENVOLIMENTO
$\begin{aligned} & \text { SISTEMA } \\ & \text { E MEIO AMBIENTE }\end{aligned}$

\title{
Análise do desempenho de reservatório de uso múltiplo: estudo de caso na sub-bacia Billings
}

\section{Multipurpose reservoir performance analysis: a case study on the Billings sub-basin}

Shevine Silva Oliveira RISSO ${ }^{*}$, Patrícia Teixeira Leite ASANOํ, Ludmilson Abritta MENDES², Eduardo Lucas SUBTIL $^{1}$, Maria Cleofé Valverde BRAMBILA ${ }^{1}$

${ }^{1}$ Universidade Federal do ABC (UFABC), Santo André, SP, Brasil.

${ }^{2}$ Universidade Federal de Sergipe (UFS), São Cristóvão, SE, Brasil.

*E-mail de contato: shevine.oliveira@gmail.com

Artigo recebido em 14 de agosto de 2017, versão final aceita em 19 de junho de 2018.

RESUMO: O presente estudo analisou o desempenho do Reservatório Billings, inserido na bacia do Alto Tietê - São Paulo, quanto à sua capacidade de atender as demandas de abastecimento urbano e de geração de energia elétrica concomitantemente. Para isso, foram considerados três cenários de operação para o Reservatório: no primeiro, adotou-se diferentes valores de transferência de água para o Reservatório, além de demanda consuntiva fixa; no segundo, a transferência de águas foi suprimida e considerou-se diferentes demandas consuntivas; no terceiro, empregou-se o reúso potável indireto da água como auxílio para recarga do Reservatório, e considerouse diferentes demandas consuntivas. Os indicadores de desempenho estatísticos confiabilidade, resiliência e vulnerabilidade e o Índice de Sustentabilidade Hídrica foram calculados. Os resultados obtidos para o Cenário 1, pelo cruzamento entre os fatores critérios de desempenho versus bombeamento do reservatório, indicaram que a confiabilidade, a resiliência e o Índice de Sustentabilidade Hídrica aumentaram, ao passo que a vulnerabilidade do sistema diminuiu significativamente. No Cenário 2, observou-se que o aumento da demanda hídrica implica em reduções significativas da confiabilidade, da resiliência e da sustentabilidade hídrica e um aumento da vulnerabilidade do sistema. Por último, o Cenário 3 demonstrou que a recarga do Reservatório por meio da água de reúso proporciona melhorias no seu desempenho se comparado ao Cenário 2, e beneficia a redução dos impactos ambientais provindos do lançamento dos esgotos na Billings. Concluiu-se que o planejamento de um sistema de Reservatório é um fator essencial para que ele possa satisfazer as múltiplas demandas e que, como uma solução parcial a fim de aumentar o aporte de água na Billings, a inserção da prática do reúso da água é uma ideia importante a ser considerada, pois poderá auxiliar na alimentação hídrica do Reservatório até que a transferência de águas dos rios Tietê e Pinheiros volte a ser 
viável, como foi projetado inicialmente.

Palavras-chave: reservatório múltiplo uso; planejamento energético; recursos hídricos; indicadores de desempenho; índice de sustentabilidade hídrica.

ABSTRACT: As a result of economic development, multiple and extensive uses of water resources have caused an imbalance between the demands and the water supply in reservoirs. Thus, the present study analyzed the performance of the Billings Reservoir, located in the Alto Tietê basin - São Paulo, in terms of meeting the demands of urban water supply and electricity generation simultaneously. For that, three operating scenarios for the Reservoir were considered: the first, different numbers of water transfer and fixed consumptive demand were adopted; in the second, the transfer of water was suppressed and different consumptive demands were considered; the third, used the indirect potable water reuse as an aid to recharge the Reservoir and considered different consumptive demands. The statistical performance indicators reliability, resilience, vulnerability and Water Sustainability Index were calculated. And based on the results obtained for Scenario 1, the curve of performance criteria versus reservoir pumping, reliability, resilience, and water sustainability index increased and vulnerability in the system reduced significantly. The Scenario 2, according to the curve of performance criteria versus demand flow, demonstrated that the increase in water demand implies significant reductions in reliability, resilience and water sustainability, and reflects in the increase of system vulnerability. Finally, the Scenario 3 demonstrated that the recharge of the reservoir when employing reuse water provides improvements in reservoir performance compared to Scenario 2 and promotes the reduction of environmental impacts from the release of the sewage system into Billings. It was possible to observe the relevant role of the water supply to the Billings Reservoir, in terms of meeting its demands and water sustainability when adopting the multiple use of water.

Keywords: multipurpose reservoir; energy planning; water resources; performance indicators; index of water sustainability.

\section{Introdução}

O processo de industrialização e desenvolvimento econômico proporcionou a urbanização do País ao mesmo tempo em que intensificou o uso dos recursos hídricos. Ele aumentou a quantidade de água demandada e diversificou suas utilizações, com uma demanda crescente para setores como o de irrigação, o industrial, o elétrico e o de saneamento, sem contar a demanda consuntiva de água para o abastecimento público, que cresce por causa do aumento do consumo nas cidades. Em determinadas regiões do País, o conflito por causa dos usos múltiplos da água se tornaram concorrentes e com potencial para gerar conflitos entre os usuários (Mendes, 2012).

Dentro desse panorama as demandas médias de água para a população urbana, que segundo as projeções do ATLAS Brasil - Abastecimento Urbano de Água, desenvolvido pela ANA - Agência Nacional de Água, obtidas a partir do cruzamento de dados da Pesquisa Nacional de Saneamento Básico, do Censo 2000 do IBGE e do Sistema Nacional de Informações sobre Saneamento, a demanda hídrica média para o abastecimento populacional urbano, alcançará o valor total de $630 \mathrm{~m}^{3} / \mathrm{s}$ no ano de 2025 . As Regiões Sudeste e Nordeste, juntas, responderão por $71 \%$ de toda a demanda projetada para 2025, e, ainda, na Região Sudeste, só o Estado de São Paulo 
será responsável por $50 \%$ da demanda média para abastecimento urbano no Brasil (ANA, 2010; 2017).

Entre 2013 e 2015, sem um plano de planejamento integrado de recursos adequado, a crise hídrica intensificou os discursos que buscavam demonstrar a necessidade de harmonização dos diversos usos e sistemas de recursos hídricos por meio de uma base de gerenciamento integrado entre os diversos setores. Ficou claro a necessidade de se considerar todos os usos concorrentes entre os beneficiados na tomada de decisão para a expansão e a operação dos sistemas de reservatórios com uso múltiplo (Lira \& Cândido, 2013).

Segundo o Plano Nacional de Energia - 2030, o estudo do grau de convergência da sustentabilidade do uso dos recursos naturais é de suma importância. Principalmente no que tange os recursos que apresentam usos múltiplos, ou que são passíveis de disputa pelos diversos grupos econômicos e sociais, observa-se a necessidade de uma ampla discussão sobre as prioridades de uso (EPE, 2008).

No Brasil, um dos principais usos dos recursos hídricos está voltado para a geração de energia elétrica, já que, segundo o Balanço Energético Nacional - BEN (EPE, 2016), ano base 2015, os 359,743 TWh de energia elétrica gerada foi proveniente de usinas hidroelétricas. Isso representa cerca de $61,86 \%$ da oferta interna de energia elétrica no País, avaliada num total de 581,48 TWh em 2015.

A capacidade de geração de energia instalada no Brasil foi avaliada em 150,61 GW em 2017 (ANEEL, 2017), e a parcela referente às hidrelétricas foi de 91.237 MW, ou 64,7\% do total, o que demonstra a importância da utilização da água para a população brasileira, principalmente por se tratar de uma fonte renovável. O Plano Nacional de Energia 2030 (EPE, 2008) prevê que a demanda de energia provinda de fonte hidráulica aumentará de forma sustentada até 2030, devido ao aumento da geração pública.

Diante do contexto apresentado, este estudo buscou abordar o conflito estre os setores de energia elétrica e o de abastecimento urbano quanto às suas demandas voltadas ao Reservatório Billings. Este foi construído na década de 1930, na bacia do Alto Tietê - SP, tendo como finalidade aumentar a capacidade de geração de energia elétrica da Usina Hidrelétrica de Henry Borden, localizada em Cubatão - SP. Para que o Reservatório fornecesse a demanda de água necessária para a geração total na usina, foi realizada a obra de transferência de águas dos rios Tietê e Pinheiros, proporcionando assim um grande potencial hídrico para o sistema.

A localização estratégica do Reservatório Billings na Região Metropolitana de São Paulo (RMSP) passou a beneficiar também o setor de abastecimento público de água, que em 1958, através do bombeamento do seu braço Rio Grande, começou a atender a região do ABC paulista (SABESP, 2009). A partir de então, a demanda consuntiva de água tornou-se crescente, fazendo parte, inclusive, do aporte de água no auxílio ao Sistema Cantareira na sua nova solicitação de renovação de outorga (SABESP, 2015a).

Com o objetivo de ampliar o uso do Reservatório Billings para fins de abastecimento público, a SABESP implantou, a partir do ano 2000, um sistema de captação e transferência de água da Billings para o Reservatório Guarapiranga, através do Braço do Taquacetuba, que perdura até os dias atuais.

A expansão da utilização do Reservatório para o abastecimento público defronta-se com a questão da qualidade das águas e com o uso dos recursos hídricos para a geração de energia elétrica nas usinas 
Henry Borden. Entre os seus braços, destaca-se o braço do rio Pequeno, incluído no Plano Diretor de Abastecimento de Água da SABESP para a RMSP, como uma alternativa de grande interesse, especialmente para a região do $\mathrm{ABC}$ paulista (São Paulo, 2014).

Devido ao aumento da população na RMSP e à falta de infraestrutura na ocupação territorial, não se evitou a crescente poluição dos rios Tietê e Pinheiros, tampouco os lançamentos de esgotos domésticos e industriais diretamente no Reservatório Billings, o que fez com que a qualidade de sua água ficasse comprometida. Dessa forma, visando a medidas eficazes para impedir o bombeamento de águas servidas na Billings, foi regulamentada a Resolução Conjunta SMA/SES n ${ }^{\circ}$. 3/1992, atualizada em 2010 pela Resolução SMA/SSE - 002/2010, que suspendeu por tempo indeterminado o bombeamento das águas do rio Pinheiros para a Represa Billings (São Paulo, 1992; 2010).

Essa medida acabou tendo um impacto significativo na demanda de água para a geração de energia elétrica, que, segundo a EMAE - Empresa Metropolitana de Águas e Energia, reduziu em aproximadamente $75 \%$ a possibilidade de geração de energia elétrica na Henry Borden.

Nesse cenário, a preocupação se volta para necessidade de criação de estratégias de planejamento e operação do Reservatório Billings que possam garantir o atendimento dos seus usos múltiplos. Uma das soluções seria a adoção de estratégias que visem tratar e reusar a água dos esgotos já disponíveis na Região Metropolitana de São Paulo, o que poderia contribuir substancialmente para o aumento da robustez do sistema Billings porque reduziria as condições de estresse hídrico associadas à redução da disponibilidade hídrica utilizados para os usos consuntivos (Hespanhol \& Bezerril Jr., 2008).

A adoção do modelo de reúso potável indireto planejado tem se tornado uma importante ferramenta no gerenciamento dos recursos hídricos e de políticas ambientais (Fonseca, 2001; Tosetto, 2005). Nesse modelo, a água, após o seu tratamento, é reintroduzida nos rios e lençóis freáticos, a fim de ser utilizada junto ao reservatório de forma controlada, no atendimento de algum uso que seja benéfico à sociedade.

Desse modo, a aplicação do reúso da água na sub-bacia Billings atuaria em dois aspectos: primeiro, como um recurso hídrico complementar na melhoria do potencial hídrico do sistema; segundo, como um instrumento para redução dos impactos ambientais provocados pela poluição dos corpos hídricos derivados do lançamento de esgoto.

Para que estratégias como essas sejam aplicadas, um aspecto importante a ser levado em consideração é a análise da capacidade de desempenho do reservatório sob a ótica da variedade de condições esperadas durante a sua vida operacional. Assim, o presente trabalho objetivou o estudo do desempenho do Reservatório Billings, a partir de diferentes cenários de demandas hídricas para o setor elétrico e para o abastecimento de água urbano e de formas de contribuição hídrica, seja a partir da transferência das águas do rio Pinheiros, seja com base no método do reúso potável indireto planejado.

Para isso, determinou-se e avaliou-se as condições de funcionamento do sistema Reservatório com base no seguinte conjunto de indicadores: confiabilidade, resiliência e vulnerabilidade, tal como definidos por Hashimoto et al. (1982), e o Índice de Sustentabilidade Hidrica proposto por Loucks (1997). A partir do comportamento do desempe- 
nho que o Reservatório apresentou nos diferentes cenários, buscou-se demonstrar a importância do planejamento da demanda por recurso hídrico sob a ótica da dinâmica da operação do Reservatório Billings dentro dos diferentes contextos de uso dos recursos hídricos como sendo um corpo receptor de esgotos e objeto de transferências e reúso de águas.

\section{Caracterização do Reservatório Billings}

Morfologicamente, a sub-bacia Billings apresenta-se no formato dendrítico, porque possui diversos braços ligados a um corpo central alongado e estreito, como pode ser visto na Figura 1.

Em função dessa característica, a afluência de água ocorre preferencialmente ao longo do canal central, o que provoca, na maior parte do tempo, um isolamento do volume de água presente nos seus braços. Esta particularidade fez com que cada braço da Billings se constituísse como um reservatório à parte, com características e dinâmicas particulares.

Grande parte de suas nascentes localizam-se na porção sul e leste da bacia, próximas ao reverso das escarpas da Serra do Mar, com altitudes máximas em torno dos $900 \mathrm{~m}$. A porção oposta da bacia possui uma rede de drenagem bem menor, com cursos d'água curtos e de perfil longitudinal pouco expressivo, onde o desnível topográfico é em média de $50 \mathrm{~m}$, da nascente à foz. Os principais formadores da bacia hidrográfica da Billings são: Rio Grande ou Jurubatuba, Ribeirão Pires, Rio Pequeno, Rio Pedra Branca, Rio Taquacetuba, Ribeirão Bororé, Ribeirão Cocaia, Ribeirão Guacuri, Córrego Grota Funda e Córrego Alvarenga (São Paulo, 2010).

O Reservatório Billings é o maior reservatório superficial de água doce existente na RMSP. Possui

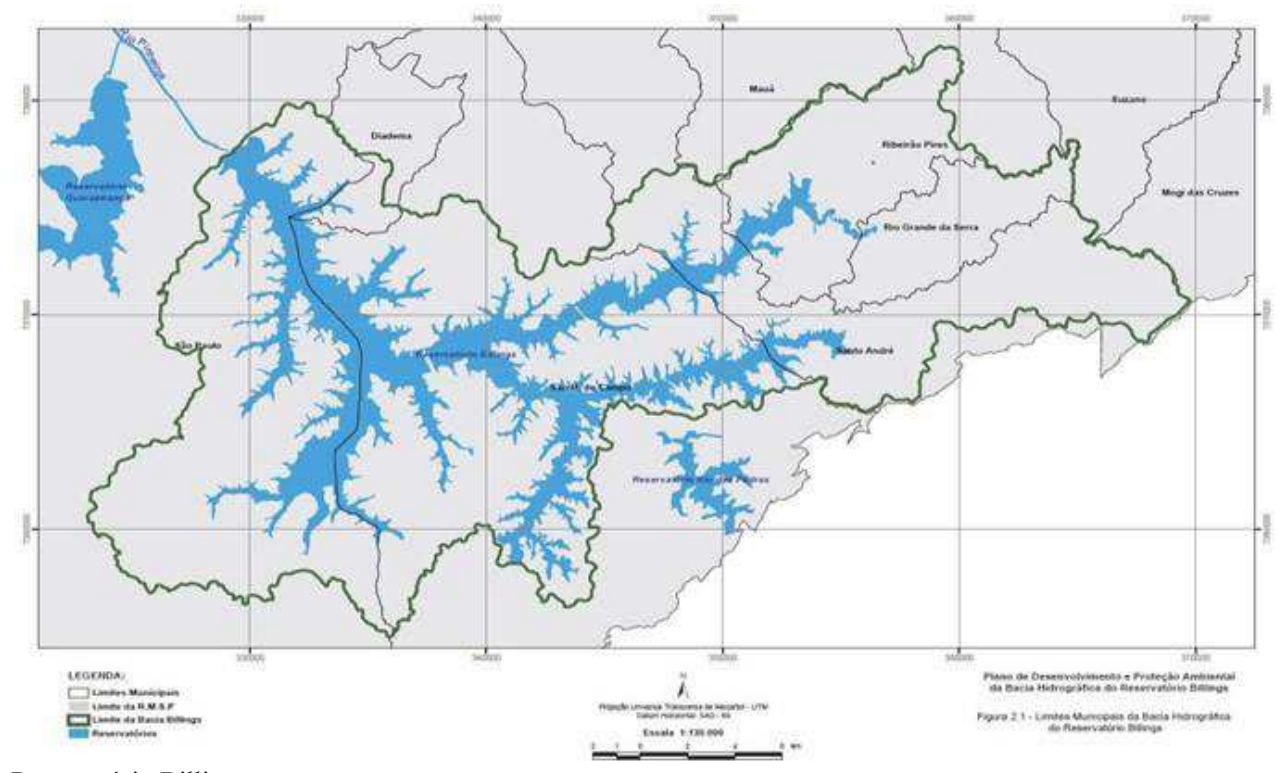

FIGURA 1 - Reservatório Billings.

FONTE: São Paulo (2010). 
$108,14 \mathrm{~km}^{2}$ de espelho d'água, que corresponde a $18,6 \%$ da área total da bacia hidrográfica. Recobre uma área de $130 \mathrm{~km}^{2}$ com capacidade para armazenamento de 1,1 bilhões de metros cúbicos de água, quando atinge a cota máxima de 746,5 m do nível do mar. Ele foi idealizado a partir dos estudos de implantação do "Projeto da Serra" pelo engenheiro Asa White Kenney Billings, que previa a utilização das águas da bacia do Alto Tietê para geração de energia elétrica na UHE de Henry Borden, localizada em Cubatão, aproveitando o desnível de 750 $\mathrm{m}$ da Serra do Mar, como apresentado na Figura 2.

Desde 5 de outubro de 1992, atendendo à carta magna paulista, que foi regulamentada pela Resolução Conjunta SMA/SES n $3 / 92$ de 04 de setembro de 1992, das Secretarias do Meio Ambiente (SMA) e Secretaria de Energia e Saneamento (SES), e atualizada pela Resolução SMA-SSE-02, de 19 de fevereiro de 2010, o bombeamento das águas do rio Pinheiros para a represa Billings está suspenso por tempo indeterminado, prevendo danos a pessoas e bens, decorrentes do excesso ou falta d'água no sistema híbrido da Bacia do Alto Tietê e das bacias a ela interligadas (São Paulo, 1992; 2010).

Segundo a Resolução, os órgãos responsáveis pela operação do sistema ficam autorizados a proceder com o bombeamento das águas do Rio Pinheiros para a Represa Billings nas seguintes situações de emergência:

- Sobrelevação de 20 a $30 \mathrm{~cm}$ do nível d'água do Rio Tietê, a montante da Barragem Móvel, ou no Canal Pinheiros Inferior;

- Sobrelevação mínima de $30 \mathrm{~cm}$ do nível d'água do Canal Pinheiros Superior;

- Descarga do Reservatório do Guarapiranga para o Canal Pinheiros Superior, para controle de cheias desse reservatório.

Os Secretários de Estado do Meio Ambiente e de Energia e Saneamento poderão, conjuntamente, determinar a retomada do bombeamento, pelo tem-

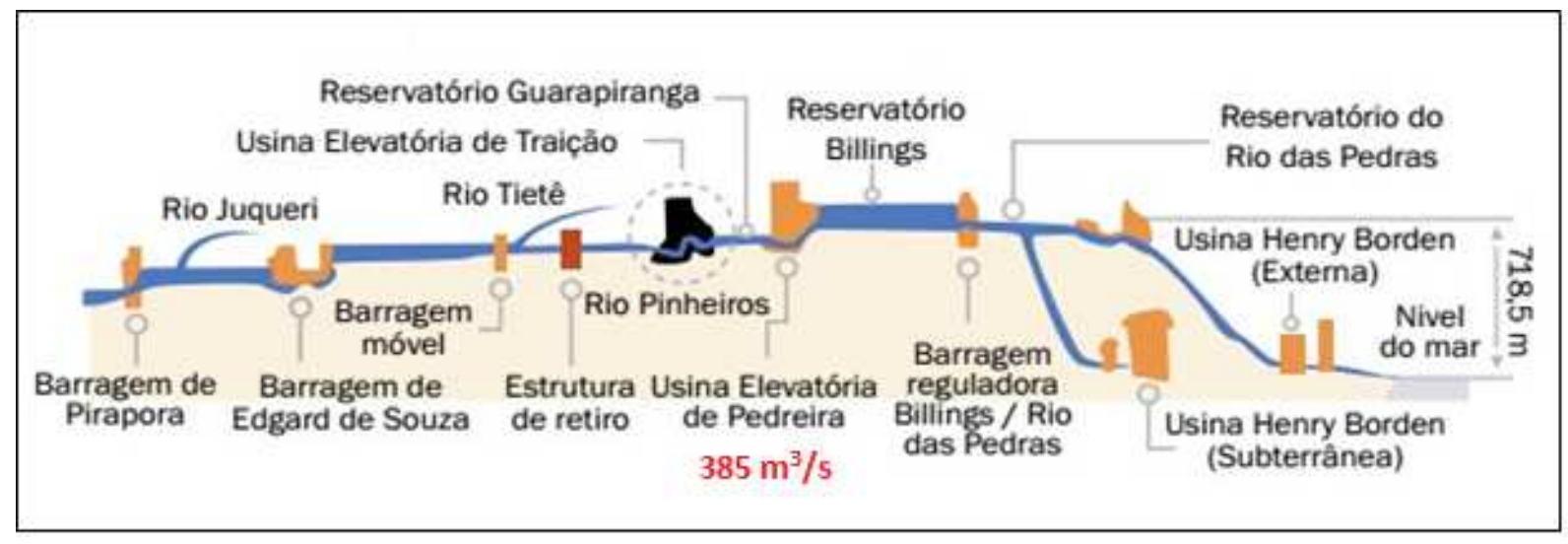

FIGURA 2 - Sistema Hidráulico da EMAE: perfil do Sistema da Concessão do Projeto Serra.

FONTE: EMAE (2016a). 
po necessário para prevenir ou remediar os possíveis danos, nas seguintes situações de emergência:

- Queda da cota na tomada d'água da Usina Henry Borden a níveis insuficientes para assegurar o fornecimento de energia elétrica em situações emergenciais;

- Formação de espumas surfactantes no Rio Tietê, a jusante de Edgard de Souza, que venham a extravasar o espelho d'água;

- Formação de "bloom" de algas nos corpos hídricos da Região Metropolitana de São Paulo e Médio Tietê, comprometendo sua qualidade para fins de abastecimento público.

\subsection{Demandas da UHE Henry Borden para produção de energia elétrica}

De acordo com Gramulia Jr. (2009), para aproveitar a máxima potência outorgada de $889 \mathrm{MW}$ na UHE Henry Borden, são necessários $157,2 \mathrm{~m}^{3} / \mathrm{s}$, utilizando-se a produtibilidade de 5,654 $\mathrm{MW} /\left(\mathrm{m}^{3} / \mathrm{s}\right)$. Em relação à energia assegurada de $127,7 \mathrm{MW}$, a quantidade de água necessária é de $22,6 \mathrm{~m} 3 / \mathrm{s}$, o que representa menos de $15 \%$ da vazão para a máxima geração de energia elétrica.

Para atender as condições estabelecidas na Resolução Conjunta SMA/SES no 3/92, a geração de energia elétrica no complexo de UHE Henry Borden fica reduzida em aproximadamente de $75 \%$ de sua capacidade máxima, devido aos problemas de poluição das águas dos rios Pinheiros e Tietê (Gramulia Jr., 2009; EMAE, 2016b).

A Usina possui grande capacidade e tem facilidade de geração de potência reativa para o equilíbrio da tensão no sistema, podendo trabalhar em Black
Start, ou seja, em situações de perda total de geração de energia elétrica no SIN - Sistema Interligado Nacional. Ela tem a capacidade de auxiliar os procedimentos de energização e recomposição desse sistema por ser projetada para trabalhar sozinha, já que possui um gerador interno para os sistemas auxiliares.

Vale ressaltar também o importante fornecimento de água doce, por meio do turbinamento da usina, que supre aproximadamente $60 \%$ da necessidade de água para a Região da Baixada Santista.

\subsection{Demandas do Reservatório Billings para o abastecimento público urbano}

A Região Metropolitana de São Paulo localiza-se nas cabeceiras da bacia do rio Tietê, uma região de baixa disponibilidade hídrica específica, que exige importar $32,3 \mathrm{~m}^{3} / \mathrm{s}$ de bacias hidrográficas adjacentes. Dos 39 municípios, 31 pertencem ao Sistema Integrado de Abastecimento de Água operado pela Companhia de Saneamento básico de São Paulo - SABESP (ANA, 2010).

Segundo a SABESP (2015b) as demandas por abastecimento urbano atingem, por várias horas, picos de $77-78 \mathrm{~m}^{3} / \mathrm{s}$, acima da capacidade nominal do conjunto do sistema produtor. Nestas ocasiões, o abastecimento é garantido pela otimização da operação das estações de tratamento e pelos reservatórios da rede de distribuição. Com efeito, o crescimento populacional apresenta uma curva contínua, exigindo, em números aproximados, um acréscimo anual na produção de água de pelo menos $0,5 \mathrm{~m}^{3} / \mathrm{s}$.

Já as projeções do Plano Diretor de Aproveitamento de Recursos Hídricos para a Macrometrópole Paulista de 2013 indicaram que a população dessa 
região passará de 30,8 milhões de habitantes em 2008 para 37 milhões em 2035. Esse crescimento, juntamente com o setor industrial e a irrigação, deverá incrementar as demandas de água em cerca de $60 \mathrm{~m}^{3} / \mathrm{s}$, num cenário denominado Tendencial (DAEE, 2013).

Os cenários para 2025 e 2035 de demanda de água para a RMSP, de acordo com os usos urbano, industrial e de irrigação, podem ser vistos na Tabelas 1 . As diferenças de projeções das demandas do Plano Diretor do setor de abastecimento evidenciam a importância da adoção das metodologias empregadas nos estudos das demandas por água e a necessidade de transparência desses métodos.

O período extremado de escassez hídrica, que ocorreu a partir do último trimestre de 2013 e se estendeu até meados de 2015, trouxe efeitos severos para a acumulação de águas nos sistemas Alto Cotia, Alto Tietê e, principalmente, no Sistema Cantareira, levando à adoção de medidas de emergência sem precedentes para mitigar os impactos da crise nas atividades urbanas e econômicas da Região Metropolitana de São Paulo (CBH-AT, 2016; SABESP, 2015a).

A razão para essa crise, segundo Côrtes et al. (2015), foi noticiada como sendo a ocorrência de um período de estiagem e de temperaturas muito acima das normais para essa época do ano, o que explicava o baixo nível pluviométrico. Contudo, ela também foi, concomitantemente, um reflexo da deficiência no planejamento estratégico que afeta o sistema de abastecimento da Região nos últimos dez anos.

Dentro do contexto da necessidade de segurança hídrica da RMSP, o Reservatório Billings passa a ter um papel mais importante no atendimento à demanda de água para o abastecimento. Sua localização estratégica, aliada ao déficit de fontes de abastecimento para a RMSP, fazem com que a Billings se constitua numa das principais alternativas para o abastecimento de água potável da capital e de seu entorno (Little, 2003).

A primeira medida financeiramente viável para a Sabesp relacionada a esse reservatório foi a transposição das águas do seu braço Taquacetuba para o reservatório Guarapiranga, concretizada no final dos anos 90, no intuito de suprir a demanda por água para o consumo humano sem alocar grandes investimentos tecnológicos para tratamento dos efluentes lançados nos cursos d'água que passam pela capital paulista (PROAM, 2009).

Segundo a Deliberação CBH-AT n ${ }^{\circ} 26$, de 28 de junho de 2016, e a proposta de renovação de outorga do Sistema Cantareira pela SABESP, a Bacia Billings tem sido considerada no planejamento

TABELA 1 - Demanda Projetada para o Cenário Tendencial (m3/s).

\begin{tabular}{|c|c|c|c|c|c|c|c|c|c|c|c|c|}
\hline \multirow[t]{2}{*}{ Ano } & \multirow{2}{*}{$\begin{array}{c}\text { População } \\
\text { (habitantes) } \\
\text { Total }\end{array}$} & & \multicolumn{9}{|c|}{ Demanda de água $\left(\mathrm{m}^{3} / \mathrm{s}\right)$} & \multirow[t]{2}{*}{ Total } \\
\hline & & \multicolumn{3}{|c|}{ Sistema Integrado } & \multicolumn{3}{|c|}{ Sistemas Isolados } & \multicolumn{3}{|c|}{ RMSP - Total } & Irrig. & \\
\hline 2025 & 22.206 .211 & 21.416 .722 & 78,66 & 37,78 & 3,01 & 1,43 & 0,42 & 1,53 & 80,09 & 38,20 & 4,24 & 122,84 \\
\hline 2035 & 22.938 .472 & 22.657 .146 & 81,26 & 38,30 & 3,01 & 1,58 & 0,46 & 1,53 & 82,84 & 38,76 & 4,54 & 126,15 \\
\hline
\end{tabular}

FONTE: DAEE (2013). 
dos investimentos que visam aumentar a segurança hídrica da Região Metropolitana de São Paulo. O reservatório já possui outorga para transferir 2 $\mathrm{m}^{3} / \mathrm{s}$ ao Sistema Guarapiranga, porém a SABESP solicita o aumento para $5 \mathrm{~m}^{3} / \mathrm{s}$, dado que o sistema instalado de captação e recalque permite essa vazão (SABESP, 2015b).

Em setembro de 2015, iniciou-se a operação de transferência de água bruta da Represa do Rio Grande para a represa de Taiaçupeba, no sistema Alto Tietê, com contribuição da represa Billings por meio do bombeamento de água do braço do Rio Pequeno, ampliando a segurança hídrica do Sistema Alto Tietê pela possibilidade de aportar vazões máximas próximas a $4,0 \mathrm{~m}^{3} / \mathrm{s}$. Sua estação de tratamento de água também foi ampliada recentemente, passando de $4,8 \mathrm{~m}^{3} / \mathrm{s}$ a $5,5 \mathrm{~m}^{3} / \mathrm{s}$. Esse Sistema abastece a maior parte da região do $\mathrm{ABC}$, incluindo São Bernardo do Campo, Diadema, parte de Santo André e de Ribeirão Pires.

A obra de transferência de $4 \mathrm{~m}^{3} / \mathrm{s}$ da represa Billings para a represa Taiaçupeba corresponde parcialmente a uma antecipação de captação prevista no Plano Diretor de Abastecimento de Água (Sistema Rio Pequeno-Billings, de $2,2 \mathrm{~m}^{3} / \mathrm{s}$, com entrada em operação prevista para 2019/20) (SABESP, 2015a). No planejamento estabelecido pelo Plano Diretor, essa vazão deveria ser aduzida à Estação do Sistema Rio Grande (que necessitará ser ampliada), opção que permanece válida para o abastecimento da região do $\mathrm{ABC}$. A elevatória e a adutora de interligação entre as represas Rio Grande e Taiaçupeba serão mantidas em funcionamento, por estarem diretamente vinculada à segurança hídrica, principalmente do Sistema Alto Tietê (São Paulo, 2014).

\subsection{O reúso da água como fonte de recarga para o Reservatório Billings}

Segundo o Programa de Reúso dos Efluentes das ETEs da RMSP (SABESP, 2015b), o reúso das águas se caracteriza como uma ação importante para preservar ou substituir a água tratada para consumo humano no caso de usuários industriais e de serviços que não necessitem de água potável, como serviços de limpeza de ruas, rega de jardins e praças, entre outros.

O Plano Diretor de Aproveitamento de Recursos Hídricos para a Macrometrópole Paulista afirma que tanto o crescimento da população da RMSP, como as expansões dos setores industrial e da agricultura irrigada deverão acarretar um aumento na demanda de água, o que exige que, em contrapartida, sejam ampliados os investimentos contínuos em controle de perdas, no uso racional da água e no reúso (DAEE, 2013).

De acordo com Hespanhol \& Bezerril Jr. (2008), a efetiva implementação da prática de conservação e reúso de água no Estado de São Paulo se vincula ao desenvolvimento de três ações básicas:

$\mathbf{1}^{\mathbf{}}$.) Vontade política: as secretarias voltadas ao meio ambiente, saneamento e energia devem implementar em conjunto ações para estimular, promover e desenvolver tecnologias que favoreçam práticas de reúso da água em todos os setores estaduais. Posteriormente, devem estudar ações específicas para subsidiar a prática através da redução da cobrança pelo uso da água bem como das tarifas pelo fornecimento de água potável daquelas entidades e empresas que implantarem ações efetivas de conservação e reúso de água. 
$\mathbf{2}^{\mathbf{0}}$.) Arcabouço legal: a implementação da prática de reúso da água necessita ser suportada por legislação específica que defina as suas modalidades, os padrões de qualidade da água para cada uma delas e os respectivos códigos de prática, além de definir os critérios para licenciamento, os mecanismos de controle e o sistema de informações.

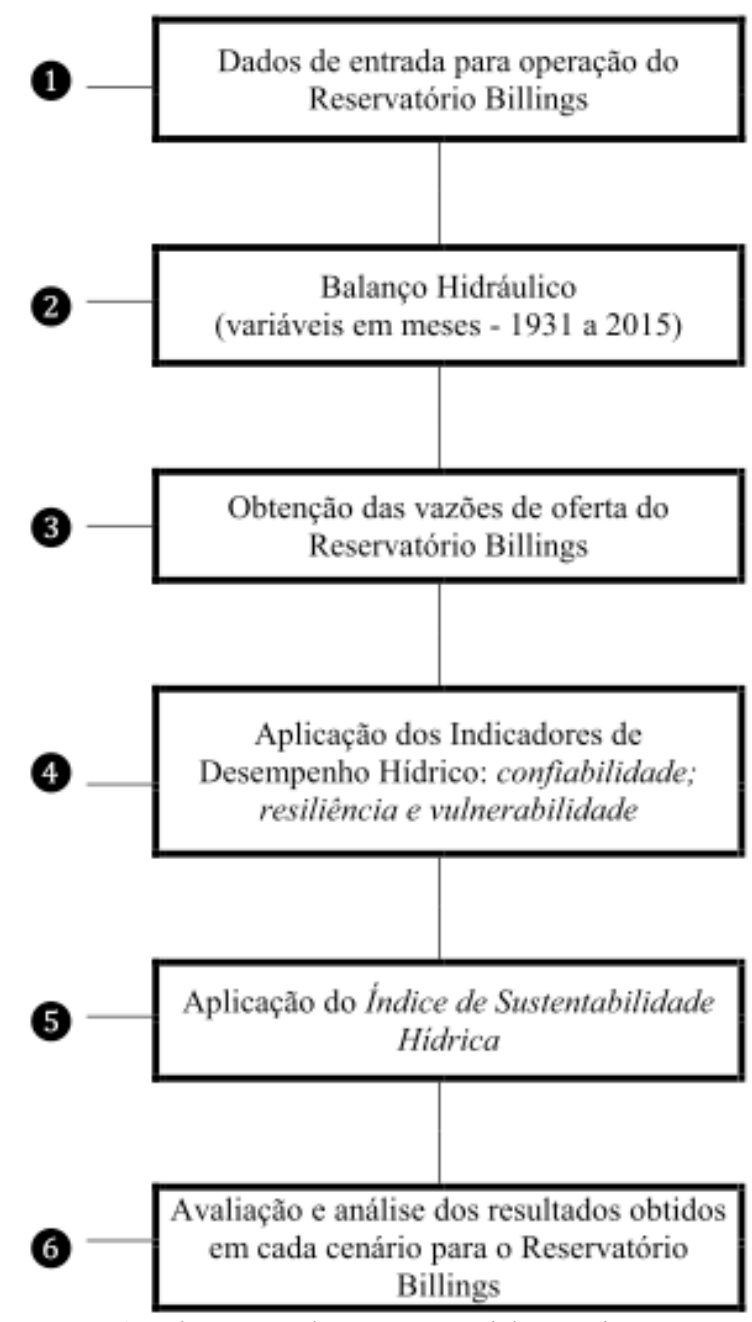

FIGURA 3 - Fluxograma da estrutura geral da pesquisa. $3^{\circ}$.) Plano Diretor de Reúso de Água: Paralelamente a esses desenvolvimentos, um Plano Diretor de Reúso de Água poderia ser elaborado, abrangendo de início a RMSP e, posteriormente, todo o Estado de São Paulo.

\section{Metodologia}

\subsection{Estrutura geral}

O desenvolvimento do presente trabalho seguiu as etapas descritas na Figura 3. As etapas se repetiram para cada um dos três cenários adotados para análise, com exceção da primeira (1), que foi a etapa de coleta de dados de entrada da operação do Reservatório. Foram três os cenários aplicados para a realização do balanço hidráulico: o primeiro considerou as condições ideais, o segundo a condição atual e o último adotou o reúso da água como proposta para melhoria do desempenho do reservatório.

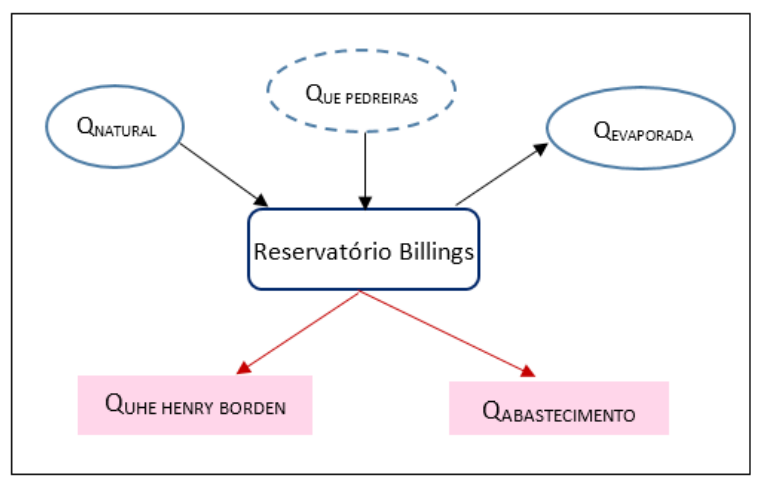

FIGURA 4 - Diagrama esquemático do Balanço Hidráulico simplificado para o Reservatório Billings. 


\subsection{Balanço hidráulico}

De modo esquemático, o balanço hidráulico pode ser apresentado de acordo com a Figura 4, na qual Q representa a vazão no sistema Reservatório Billings e $\mathrm{Q}_{\text {UE PEDREIRAS }}$ apresenta-se em linhas pontilhadas, porque a contribuição de sua vazão está restrita conforme a Resolução SMA-SSE-02, de 19 de fevereiro de 2010.

A equação de conservação de massa para o balanço hidráulico de um reservatório, em um intervalo de tempo $\boldsymbol{t}$, pode ser reescrita conforme a Equação [1]:

$V_{i+t}=V_{i}+\left(Q_{a f f_{t}}-Q_{\text {def } t}\right) \cdot \Delta t+\left(P_{t}-E_{t}\right) \cdot \frac{A_{i}+A_{i+t}}{2}$

onde,

$V_{i+t}$ e $V_{i}=$ volumes de água acumulados no reservatório no início dos meses $i+t$ e $i$, respectivamente $\left(\mathrm{hm}^{3}\right)$;

$\Delta t=$ passo da discretização;

$(P-E)=$ balanço das lâminas precipitadas e evaporadas no reservatório no instante $t(\mathrm{~mm})$;

$A_{i}+A_{i+t}=$ áreas do espelho d'água no reservatório no início dos meses $i$ e $i+t$ respectivamente $\left(\mathrm{km}^{2}\right)$;

$Q_{a f t}=$ vazão afluente ao reservatório que é considerada igual a vazão natural afluente $\left(\mathrm{Q}_{\text {nat }}\right)$, dada por: , no instante $t\left(\mathrm{~m}^{3} \cdot \mathrm{s}^{-1}\right)$;

$Q_{d e f}=$ vazão defluente, que é dada pela vazão vertida no instante $t\left(\mathrm{~m}^{3} \cdot \mathrm{s}^{-1}\right)$.

A cada intervalo de tempo, a Equação [1] é resolvida para o termo $V_{i+\rho}$ considerando que as vazões afluentes nos tempos $t$ e $t+1$ são conhecidas, e considerando que há uma relação direta entre a vazão defluente e o volume armazenado (ou o nível de água do reservatório). Considerou-se esta simplificação válida, dado que foi utilizado, na operação, um intervalo de tempo mensal (jan/1931 a dez/2015), que é relativamente pequeno se for considerado o volume útil do reservatório em que foi feita a aplicação.

Os dados tomados para a aplicação dos indicadores foram os volumes finais ao logo do período de análise $\left(V_{i+t}\right)$, que foram transformados em vazão para que os valores ficassem menores e facilitassem a análise, e foram denominados de $\mathrm{Q}_{\text {oferta }}$ (vazões de oferta, $\mathrm{m}^{3} / \mathrm{s}$ ).

Esta expressão demonstra que o volume do reservatório pode aumentar e diminuir por causa de diversos fatores. Assim, considerou-se que a operação do reservatório Billings iniciou com a capacidade de armazenamento no seu volume máximo $\left(V_{\text {maxx }}\right)$ e foram realizadas simulações de forma a manter uma vazão regularizada a jusante $\left(Q_{\text {reg }}\right)$, fixada pelo operador.

Foram consideradas as seguintes restrições de operação:

- A vazão de oferta deverá ser maior ou igual a vazão regularizada: $Q_{\text {oferta }} \geq Q_{\text {reg }}$;

- Ao operar o reservatório, deve ser feita a tentativa de atender as demandas considerando o volume evaporado do reservatório. Após estas ponderações, se $V_{i+t}$ for maior que o volume máximo de operação do reservatório $\left(V_{\text {max }}\right)$, haverá vertimento.

$\mathrm{O}$ volume evaporado foi calculado a partir dos polinômios de quarto grau do Reservatório Billings, cujos coeficientes encontram-se discriminados nas Tabelas 2 e 3, junto com o saldo de evaporações líquidas médias mensais. 
TABELA 2 - Coeficientes dos polinômios do Reservatório Billings.

\begin{tabular}{ccccc}
\hline \multicolumn{5}{c}{ Curva COTA X VOLUME } \\
\hline A0 & A1 & A2 & A3 & A4 \\
\hline $7,289964 \mathrm{E}+02$ & $4,721631 \mathrm{E}-02$ & $-8,383957 \mathrm{E}-05$ & $8,244865 \mathrm{E}-08$ & $-2,923551 \mathrm{E}-11$ \\
\hline \multicolumn{7}{c}{ Curva ÁREA X COTA } & & $\mathbf{B}$ \\
\hline$-9,859709 \mathrm{E}+05$ & $4,018057 \mathrm{E}+03$ & $\mathbf{B 2}$ & $2,483119 \mathrm{E}-03$ & $0,000000 \mathrm{E}+00$ \\
\hline
\end{tabular}

FONTE: CCEE (2016).

TABELA 3 - Proposta para as Evaporações Líquidas do Reservatório Billings.

\begin{tabular}{ccccccccccccccc}
\hline \multicolumn{10}{c}{ SALDO (E-P) SOBRE O RESERVATÓRIO BILLINGS } \\
\hline & jan & Fev & mar & Abr & Mai & jun & jul & Ago & Set & Out & nov & Dez \\
\hline $\mathrm{mm}$ & 10 & 12 & 35 & 46 & 49 & 43 & 28 & 22 & 16 & 1 & -5 & 14 & \\
\hline
\end{tabular}

FONTE: CCEE (2016).

\subsection{Vazões afluentes na sub-bacia Billings}

As vazões médias naturais afluentes da sub-bacia Billings foram obtidas a partir das "séries históricas de vazões médias naturais da Billings" publicadas e validadas pelo Operador Nacional do Sistema Elétrica em sua própria página eletrônica (ONS, 2016). No estudo, os dados de entrada no balanço hídrico foram essas vazões médias naturais dentro do horizonte de 1931 até 2015.

\subsection{Restrições operativas}

O fornecimento de água para a UHE Henry Borden seguirá a restrição de defluência mínima de jusante igual a $6 \mathrm{~m}^{3} / \mathrm{s}$. Esta vazão é necessária devido à manutenção de um número mínimo de máquinas sincronizadas no sistema de usinas para o atendimento da ponta e emergências, e para a garantia de captação de água para o abastecimento na Baixada Santista.

No que diz respeito às restrições operativas, conforme o Inventário das Restrições Hidráulicas - Revisão 01 (ONS, 2016), a Billings possui a restrição de montante em função da curva de controle de cheias adotada pela EMAE, que podem variar de $744,86 \mathrm{~m}$ a $745,85 \mathrm{~m}$.

\subsection{Cenários adotados para as análises de desempenho do reservatório}

Para analisar e avaliar o desempenho do Reservatório Billings foram considerados diferentes cenários de oferta hídrica, nos quais se assumiu que o Reservatório apresentava o estado ideal de potabilidade de água para níveis de abastecimento.

- Cenário 1 - Ideal: este cenário adotou a condição ideal de operação do Reservatório, para a qual ele foi concebido inicialmente, quando, na concep- 
ção do seu projeto original, tratava o recebimento de águas provenientes da transferência advinda do sistema Tietê-Pinheiros através da UE de Pedreiras. Assim, considerou-se a contribuição das vazões de entrada no Reservatório provenientes tanto dos mananciais quanto da transferência de águas. Para fins de comparação e análise do desempenho hídrico do sistema sob o contexto ideal, foram avaliadas diferentes porcentagens de vazões de transferência de água do conjunto dos rios Tietê-Pinheiros para o Reservatório Billings.

A adoção do valor inicial mínimo de transferência baseou-se nos estudos de Gramulia Jr. (2014), que teve como objetivo a redução do custo de complementação térmica na geração de energia elétrica pela UHE de Henry Borden. O fator considerado para a minimização dos custos se baseou na transferência ótima de água dos rios Tietê e Pinheiros para o reservatório Billings, para cada mês de um período de planejamento de um ano, como apresentado na Tabela 4.

A demanda hídrica concernente ao setor elétrico prevista para o Reservatório, no contexto do Cenário 1 - Ideal, foi a vazão de $157 \mathrm{~m}^{3} / \mathrm{s}$ para a UHE de Henry Borden, que é o valor do engolimento máximo que a usina possui. Assim, isso proporciona uma condição em que a usina trabalhará durante todo o período de análise com a máxima geração de energia elétrica, o que reduz a necessidade de complementação com usinas termoelétricas. Junto com a vazão destinada ao setor elétrico, foi considerada também a demanda total de $9,5 \mathrm{~m}^{3} / \mathrm{s}$ para o abastecimento público da RMSP, que se distribuem em $4 \mathrm{~m}^{3} / \mathrm{s}$ para atender o Sistema Taquacetuba e 5,5 $\mathrm{m}^{3} / \mathrm{s}$ o Sistema Rio Grande.

- Cenário 2 - Atual: o cenário que trata da condição atual de operação do Reservatório considerou a contribuição da vazão de entrada no Reservatório proveniente apenas dos mananciais, desconsiderando a transferência de águas da UE Pedreiras. Para fins de comparação e análise do desempenho hídrico do sistema sob o contexto atual, foram avaliadas diferentes porcentagens de vazão de demanda de água no Reservatório, em função do crescimento que foi observado nas demandas pelo o abastecimento público na RMSP.

As demandas serão divididas entre fixa e variável. A demanda fixa será proveniente do setor elétrico, considerada com vazão de $6 \mathrm{~m}^{3} / \mathrm{s}$, que é a restrição mínima para a manutenção da UHE Henry Borden. A demanda variável será do setor de abastecimento público, cujos valores iniciais terão como base as demandas consuntivas adotadas pelo ONS - Operador Nacional do Sistema Elétrico para a Billings no ano de 2016, discriminados na Tabela 5.

As vazões de demanda para o abastecimento público serão aumentadas progressivamente, como nos estudos de projeção de demanda da SABESP (2015b), segundo os quais o crescimento populacional demonstra uma curva contínua, o que exige um acréscimo anual na produção de água de pelo menos $0,5 \mathrm{~m}^{3} / \mathrm{s}$. Esta evolução na demanda foi realizada para análise e comparação da evolução dos indicadores e do índice de sustentabilidade hídrica.

TABELA 4 - Vazão ótima transferida dos rios Tietê e Pinheiros para o Reservatório Billings em (m3/s).

\begin{tabular}{cccccccccccc}
\hline MAI & JUN & JUL & AGO & SET & OUT & NOV & DEZ & JAN & FEV & MAR & ABR \\
\hline$-152,69$ & $-152,69$ & $-152,70$ & $-129,00$ & $-137,25$ & $-152,69$ & $-152,69$ & $-152,68$ & $-152,58$ & $-152,69$ & $-149,46$ & $-152,69$ \\
\hline
\end{tabular}

FONTE: Gramulia Jr. (2014). 
TABELA 5 - Demanda hídrica consuntiva (m3/s) pelo ONS (2016).

\begin{tabular}{cccccccccccc}
\hline JAN & FEV & MAR & ABR & MAI & JUN & JUL & AGO & SET & OUT & NOV & DEZ \\
\hline 7,82 & 7,82 & 7,82 & 7,84 & 7,82 & 7,84 & 7,84 & 7,84 & 7,83 & 7,83 & 7,85 & 7,83 \\
\hline
\end{tabular}

FONTE: CCEE (2016).

A demanda hídrica associada à usina foi representada por um conjunto de 12 valores referentes a cada mês do ano. A partir do $13^{\circ}$ mês da operação, repetiram-se os valores da série até o final. Em relação à sazonalidade das demandas consuntivas, foi obedecida a variação mensal dos valores divulgados pelo ONS.

- Cenário 3 - Reúso da Água: este cenário considerou, além da contribuição da vazão natural dos mananciais, o reúso potável indireto como forma de recarga de água para a represa Billings. A vazão de recarga hídrica inicial se baseou na vazão de esgotos coletados nos municípios próximos ao Reservatório Billings e que são atendidos por estações de tratamento de esgotos (ETEs) inseridos na RMSP. Esses municípios estão listados na Tabela 6, junto com as respectivas vazões de esgoto coletado.

TABELA 6 - Municípios inseridos na RMSP e atendidos por ETEs, no raio de até 30km de distância da Represa Billings.

\begin{tabular}{|c|c|c|c|}
\hline Município & Nome do prestador de serviço & $\begin{array}{c}\text { Estação de tratamento de } \\
\text { esgoto }\end{array}$ & $\begin{array}{c}\text { Volume de esgoto coletado } \\
\text { no Município (ano base } \\
2015) \\
\left(1.000 \mathrm{~m}^{3} / \mathrm{ano}\right)\end{array}$ \\
\hline Diadema & \multirow{4}{*}{$\begin{array}{l}\text { Companhia de Saneamento } \\
\text { Básico do Estado de São Paulo } \\
\text { - SABESP }\end{array}$} & \multirow{4}{*}{ ETE ABC } & $13.717,46$ \\
\hline Ribeirão Pires & & & $2.853,18$ \\
\hline São Caetano do Sul & & & $9.550,39$ \\
\hline Santo André & & & $32.917,07$ \\
\hline Mauá & $\begin{array}{l}\text { Saneamento Básico do Municí- } \\
\text { pio de Mauá - SAMA }\end{array}$ & $\begin{array}{l}\text { Odebrecht Ambiental - ETE } \\
\text { Maua }\end{array}$ & $14.343,59$ \\
\hline Santo André & $\begin{array}{l}\text { Serviço Municipal de Sane- } \\
\text { amento Ambiental de Santo } \\
\text { André - SEMASA }\end{array}$ & ETE Parque Andreense & - \\
\hline Total & \multicolumn{3}{|c|}{$564.900,26$} \\
\hline
\end{tabular}

FONTE: MCid (2015). 
O esgoto coletado pelos municípios, no ano base de 2015, foi de 564.900,26 (1.000 m³/ano), que corresponde a uma vazão de aproximadamente $17,91 \mathrm{~m}^{3} / \mathrm{s}$ de contribuição para recarga do Reservatório Billings. Assim, esse valor foi fixado como valor de contribuição para recarga do Reservatório. As demandas foram variadas para o atendimento ao abastecimento de modo semelhante ao do Cenário 2 e, no que diz respeito à energia, manteve-se a demanda fixa de $6 \mathrm{~m}^{3} / \mathrm{s}$ para o setor elétrico.

\subsection{Aplicação dos critérios de desempenho}

As vazões de oferta $\left(Q_{o}\right)$ obtidas do balanço hídrico servirão como dados de entrada para realizar a estimativa dos indicadores de desempenho: confiabilidade, resiliência, vulnerabilidade e Índice de Sustentabilidade. Suas formulações estão descritas a seguir:

- Confiabilidade: Hashimoto et al. (1982) definem confiabilidade conforme a Equação [1]:

$\mathrm{Rt}=\operatorname{Prob}\left[\mathrm{X}_{\mathrm{t}} \in \mathrm{S}\right][1]$

ou seja, dado um conjunto $\left(X_{t}\right)$, a confiabilidade no tempo $\left(R_{t}\right)$ será a probabilidade da operação deste sistema pertencer a um estado satisfatório $(S)$.

- Resiliência: Hashimoto et al. (1982) definem a resiliência como uma probabilidade condicional, expressa segundo a Equação [2]:

$$
\mathrm{Re}=\operatorname{Prob}\left\{X_{t+1} \in S \mid X_{t} \in \mathrm{F}\right\} \quad[2]
$$

sendo $\left(X_{t+1}\right)$ a variável de estado do sistema considerado no momento $t+1, X_{t}$ a variável de estado do sistema considerado no momento $t$ e os termos $S$ e $F$ referem-se, respectivamente, ao sistema satisfatório e insatisfatório (falho).

- Vulnerabilidade: Hashimoto et al. (1982) definem a vulnerabilidade conforme a Equação [3]:

$$
\mathrm{Vul}^{\prime}=\frac{\sum_{j=1}^{f_{s}} \max (s j)}{f_{S}}
$$

onde $s j$ é o déficit volumétrico, ou vazão durante $j^{\text {th }}$ sequência de fracasso contínuo e $f s$ é o número de sequências de falhas contínuas.

- Índice de Sustentabilidade: esse indicador foi proposto por Loucks (1997), como descrito na Equação [4], onde, $0<I S H \leq 1$

Índice de Sustentabilidade Hidrica (ISH) = Conf $x$ $\operatorname{Res} x[1-V u l]$

[4]

\section{Resultados e discussão}

- CENÁRIO 1 - Ideal: Aplicou-se a este cenário diferentes incrementos de vazões de transferência até o valor em que se obteve 100\% de confiabilidade do reservatório. Essa evolução do desempenho do reservatório pode ser vista na Figura 5. Pode-se notar que o incremento de vazão a partir da transferência de águas confere um ganho na confiabilidade, que cresce de modo mais expressivo inicialmente, mas à medida que a demanda vai sendo atendida, o crescimento desacelera, chegando ao patamar de estabilidade. Quando houve o acréscimo de $43 \%$ na vazão de entrada do reservatório, beneficiada pelo bombeamento derivado da UE Pedreiras, obteve-se a máxima confiabilidade, com total atendimento à demanda.

$\mathrm{O}$ aumento da oferta hídrica no sistema tem reflexo na melhoria da resiliência, sendo que um incremento de $42 \%$ no bombeamento já conferiu ao sistema notáveis reduções no período de retorno do estado de falha para o estado satisfatório, passando de 4 meses para aproximadamente 1 mês. 
Quanto à vulnerabilidade, esta decresce no sistema quando ocorre um bombeamento de 150 $\mathrm{m}^{3} / \mathrm{s}(38,96 \%)$; a magnitude da falha é igual a 4,02 $\mathrm{m}^{3} / \mathrm{s}$ da vazão de demanda que deixa de ser atendida, que poderia corresponder, por exemplo, ao não atendimento na solicitação do abastecimento público do Sistema Taquacetuba, ou mesmo uma redução na produção de energia. A magnitude da falha pode ser considerada grande ou pequena dependendo do setor que deixou de ser atendido e da proporção dos impactos gerados. Mas conforme aumenta a contribuição na vazão de entrada no reservatório, a vulnerabilidade do reservatório reduz proporcionalmente.

O Índice de Sustentabilidade Hídrica cresce de acordo com a confiabilidade e a resiliência e de maneira inversa à vulnerabilidade. Importante destacar que esse Índice apresenta um rigor bastante significativo. Quando o reservatório apresenta 56,4\% de confiabilidade, 3 meses de resiliência e 1,95 m³/s, o índice demonstra uma baixa sustentabilidade para o reservatório igual a $17,8 \%$.

- CENÁRIO 2-Atual: Com base na Figura 6, é possível verificar a grande vulnerabilidade à qual o sistema fica sujeito quando ocorre o acréscimo de demandas no Reservatório, sem o bombeamento. Isso se deve à baixa contribuição dos mananciais, que não conseguem suprir as vazões de demanda. Observa-se claramente a dependência da transferência de águas para que se possa obter um melhor aproveitamento do Reservatório.

Ressalte-se que com a simples duplicação da demanda de água já se pode observar que a confiabilidade do sistema cai para $12,6 \%$, ou seja, $87,4 \%$ do sistema ficou no estado de falha, com uma resiliência de 10,3\% (9 meses aproximadamente) e uma vulnerabilidade de $8,6 \mathrm{~m}^{3} / \mathrm{s}$. Em termos de demanda para abastecimento, esse pode ser um valor considerável que deixa de ser atendido pelo o sistema Billings, o que significa dizer que $31 \%$ do total da

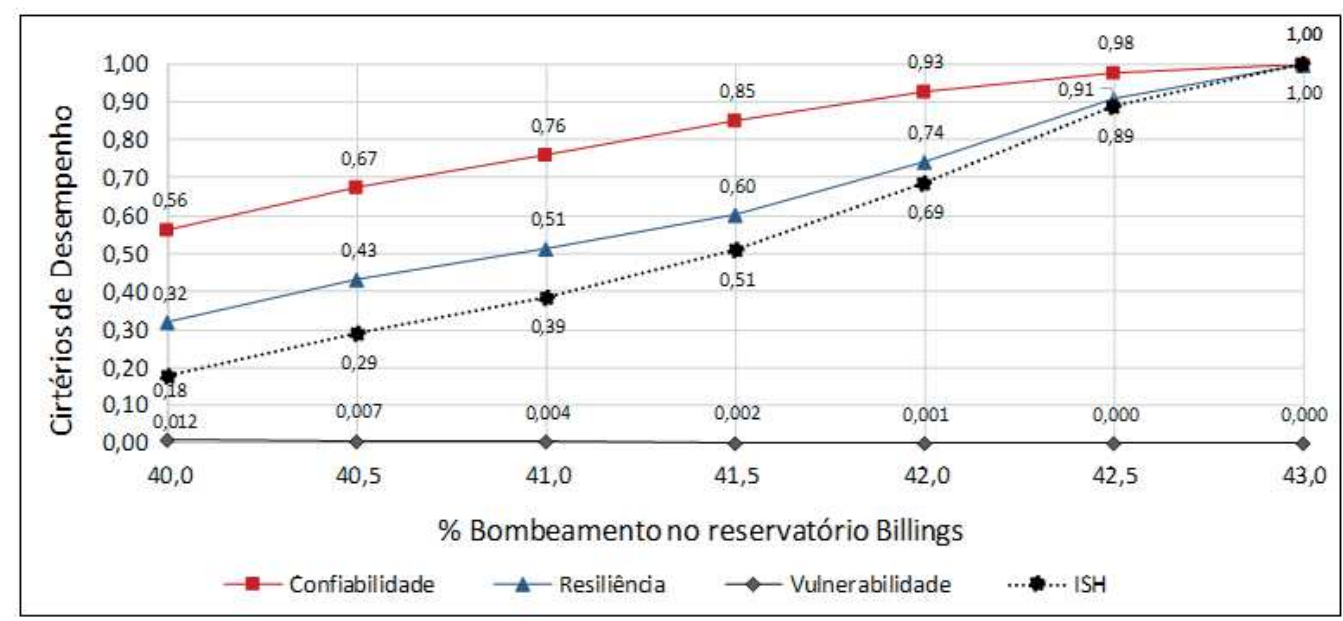

FIGURA 5 - Relação entre indicadores de desempenho e ISH do Reservatório Billings versus diferentes transferências de águas para o sistema reservatório. 
demanda deixou de ser obedecida. Observa-se uma sustentabilidade hídrica muito baixa, próxima de zero, que, devido à sua natureza multiplicativa, o ISH demonstrou como a mais sensível às menores alterações nas métricas constituintes.

Assim, os valores de desempenho, principalmente no que tange à resiliência e à vulnerabilidade, são de extrema importância e devem ser avaliadas pelo operador, cuja obrigação é analisar se a magnitude da falha é ou não significativa e quais os meios para melhorar a eficiência do seu processo, para que o impacto de uma falha não torne a produção onerosa, seja ela de energia ou de água tratada.

A magnitude de uma falha pode ser significativa, por exemplo, quando se trata de uma demanda que não possui meios de realizar sua reserva. No caso das demandas hídricas que visam garantir a geração de energia hidroelétrica, a falha no atendimento não poderia ser compensada por termoelétri- cas, por causa de sua posição geográfica ser perto de um grande centro de carga como a capital paulista, bem como de sua importância para o setor elétrico brasileiro, no caso de uma recomposição devido a apagões, conforme mostrado por Silva (2016).

Já para o caso do abastecimento de água, o não atendimento está sendo compensado atualmente por captações em outras bacias, que, de acordo com o Plano de Bacia Hidrográfica do Alto Tietê, tem sido praticada a importação de água da Bacia do rio Piracicaba, localizada ao norte da Bacia do Alto Tietê, e de outras menores nos rios Capivari e Guaratuba (FUSP, 2009). Isto leva a grandes sistemas integrados, aumentando o custo de operação e gerando uma dependência de outras bacias para atender à RMSP.

- CENÁRIO 3 - reúso da água: com base na Figura 7, pode-se observar que uma recarga de

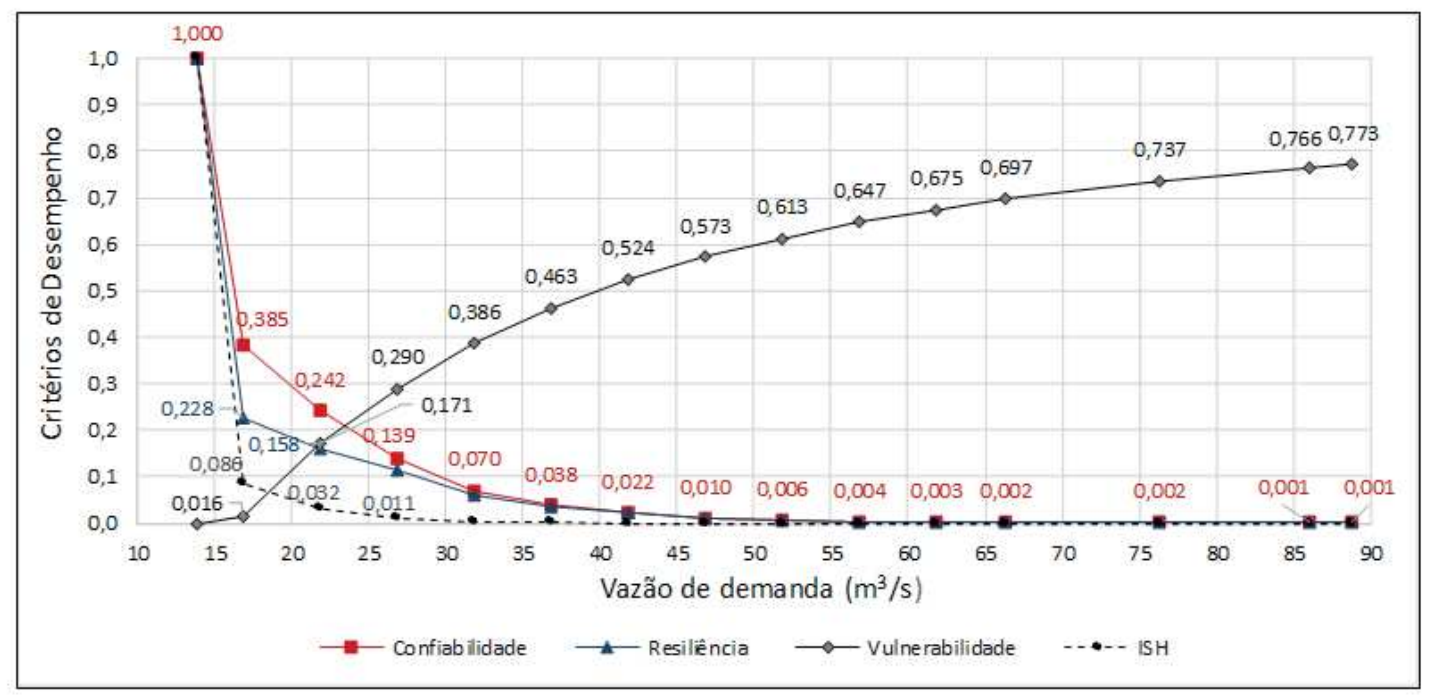

FIGURA 6 - Relação entre indicadores de desempenho e ISH do Reservatório Billings sem considerar a transferência de águas do sistema Tietê-Pinheiros-Billings versus vazões de demanda. 
$17,91 \mathrm{~m}^{3} / \mathrm{s}$ proveniente do reúso da água confere ao sistema um aumento na confiabilidade quando se tem uma demanda total aproximada de 13,83 a $18,83 \mathrm{~m}^{3} / \mathrm{s}$. Assim, o sistema conseguiria atender demandas de abastecimento de até $12,83 \mathrm{~m}^{3} / \mathrm{s}$ de produção de energia mesmo operando no seu mínimo, o que denota uma melhoria no desempenho do sistema.

Sob essas condições, o reservatório apresenta-se menos vulnerável em relação ao Cenário 2 , o que se pode ver pela curva de vulnerabilidade, que não aumenta na mesma proporção em que os outros critérios decaem.

Nesse cenário, ficou evidente que a utilização do reúso da água para recargada do Reservatório auxilia a melhoria de desempenho do sistema, tornando os conceitos de confiabilidade e resiliência menos expressivos quando comparados à real vulnerabilidade existente no reservatório, uma vez que a recarga a partir do reúso reduziu as condições de estresse hídrico que estão associadas à redução da disponibilidade de água nos mananciais utilizados para a recarga da sub-bacia Billings.

\subsection{Análise e discussão dos resultados}

A partir dos critérios de desempenho aplicados aos diferentes cenários no sistema Reservatório Billings, foi possível notar que quando o Reservatório recebe apenas a contribuição das vazões naturais dos mananciais, ele não apresenta sustentabilidade hídrica, entendida como a probabilidade de abastecer as demandas crescentes, permanentemente e sob condições satisfatórias, sejam demandas do abastecimento público, sejam do setor de energia elétrica. Logo, pode-se perceber que os três indicadores de desempenho, confiabilidade, resiliência e vulnerabilidade, possuem grande influência sobre

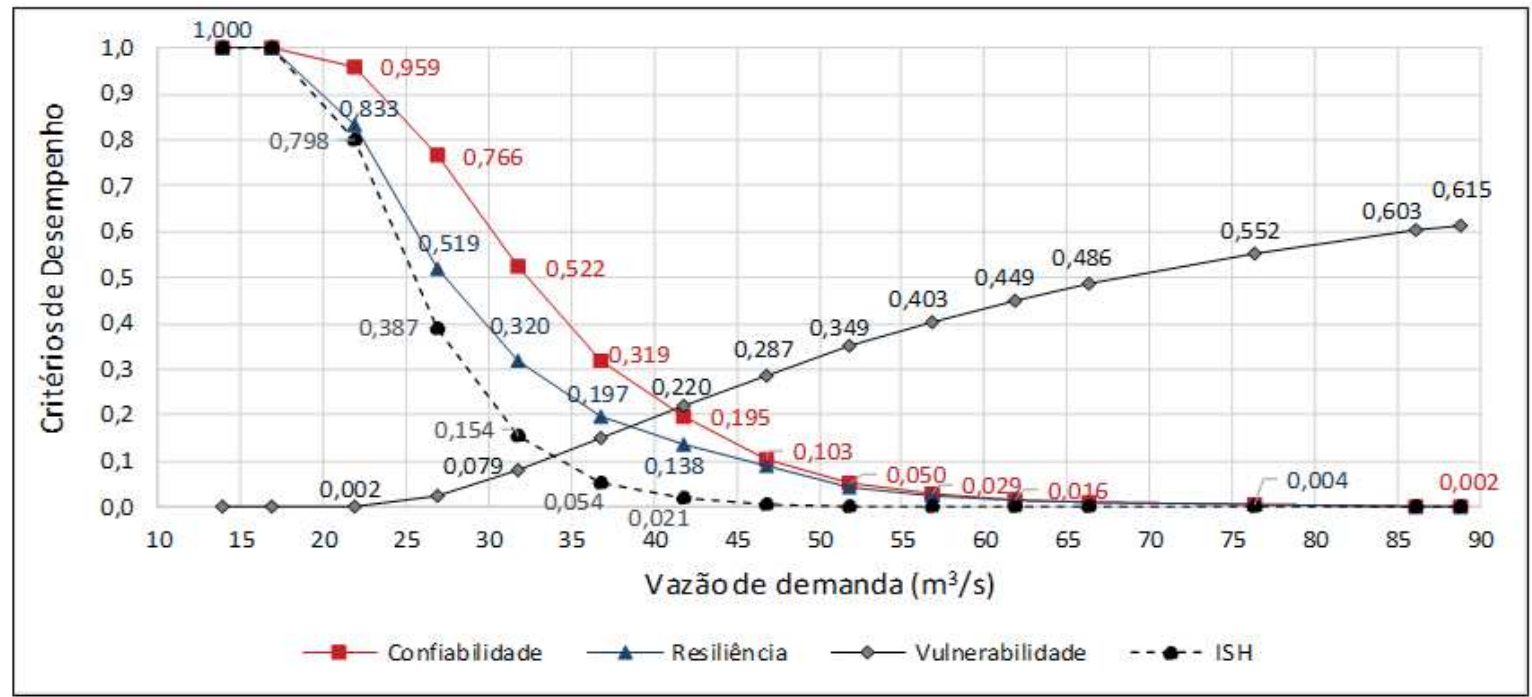

FIGURA 7 - Relação entre indicadores de desempenho e ISH do Reservatório Billings com recarga de água de reúso versus vazão de demanda. 
o ISH, como afirmado por McMahon et al. (2006), que dizem que "devido à natureza multiplicativa do Índice de Sustentabilidade Hídrica, este índice apresenta-as sensível às alterações na menor das métricas que o constitui".

Assim, pôde-se observar a fragilidade do Reservatório estudado pela falta do bombeamento provindo da UE de Pedreiras, o que torna evidente a necessidade do aporte hídrico como um fator determinante para que as demandas sejam atendidas. Observou-se também a fragilidade da condição atual da UHE de Henry Borden, que, por causa da falta de água, opera muito abaixo da sua potência instalada, o que acarreta, possivelmente, a necessidade de complementação do abastecimento por meio de termoelétricas. Isso torna onerosa a sua operação, devido ao combustível empregado, além de ser pouco sustentável, uma vez que se faz uso de fontes de geração não renováveis.

De acordo com o Cenário 1, fica evidente que a transferência de águas para o Reservatório Billings contribui de modo significativo para o ganho no desempenho, e, consequentemente, promove alta sustentabilidade hídrica. Conforme os estudos apresentados por Gramulia Jr. (2014), o ganho líquido de potência de $430 \mathrm{MW}$ devido à transferência representa um ganho para o sistema de 2,86\%, devido à alta produtibilidade de geração na UHE Henry Borden, atingindo 845 MW médios gerados. Esse ganho na produção de energia poderia ser utilizado para viabilização do tratamento de água dos rios Tietê e Pinheiros.

Como a UHE Henry Borden possui o limitador de engolimento máximo de $157 \mathrm{~m} / \mathrm{s}$, pode-se dizer que há um ganho real na transferência de água para o abastecimento urbano, e, com os benefícios de um tratamento de águas no sistema Tietê-Pinheiros, ela traria uma grande contribuição aos aportes de água para a RMSP.

Porém, para atender às condições estabelecidas na constituição estadual de geração de energia elétrica, a capacidade do complexo de UHE Henry Borden está reduzida em aproximadamente de $75 \%$ de sua capacidade máxima, devido aos problemas de poluição das águas dos rios Pinheiros e Tietê (Gramulia Jr., 2009; EMAE, 2016b).

De acordo com Gramulia Jr. (2009), para utilização da máxima potência outorgada de 889 MW, são necessários $157,2 \mathrm{~m}^{3} / \mathrm{s}$, utilizando-se a produtibilidade de $5,654 \mathrm{MW} /\left(\mathrm{m}^{3} / \mathrm{s}\right)$. Em relação à energia assegurada de $127,7 \mathrm{MW}$, a quantidade de água é de 22,6 m3/s, que representa menos de $15 \%$ da vazão necessária para máxima geração de energia elétrica. Na Tabela 7 consta o detalhamento dos valores faturados com a venda de energia elétrica, ao longo de 1993 a 2015, com exceção o ano de 2014, em que não foram divulgadas as potência e energia gerada, além do detalhamento dos valores estimados de faturamento caso produzisse a potência média anual de 504 MW fixa proposta por Gramulia Jr. (2009).

A diferença entre os dois valores totais representa o valor não faturado de $\mathrm{R} \$ 5,18$ bilhões na geração de energia, devido às restrições ambientais e que poderiam ser utilizados em projetos como a despoluição dos rios Tietê e Pinheiros, ou mesmo para viabilizar o tratamento de esgoto visando ao reúso da água. O cálculo financeiro levou em consideração o valor da tarifa média ponderada de $\mathrm{R} \$$ 63,69, dos três principais contratos em vigência no ACR - Ambiente de Contratação Regulada, informados no relatório para a CVM - Comissão de Valores Mobiliários de 2008 (Gramulia Jr., 2009). 
Enquanto políticas de despoluição das águas não são efetivadas na prática, uma solução indicada para melhorar o desempenho da Billings é a promoção da prática de reúso potável indireto planejado. Essa já tem sido uma prática desde a década de 1960 nos EUA, onde a cidade da Califórnia iniciou esse tipo de metodologia para auxiliar na recarga do seu aquífero, a fim de abastecimento da região (Hespanhol, 2015).

O reúso potável indireto planejado para a Billings se justifica por várias razões, como a recorrente redução da contribuição dos mananciais para recarga do reservatório, motivado pelos impactos do uso e ocupação do solo e da poluição; a disponibilidade de tecnologias que permitem o tratamento

TABELA 7 - Energia elétrica faturada e de potencial de faturamento.

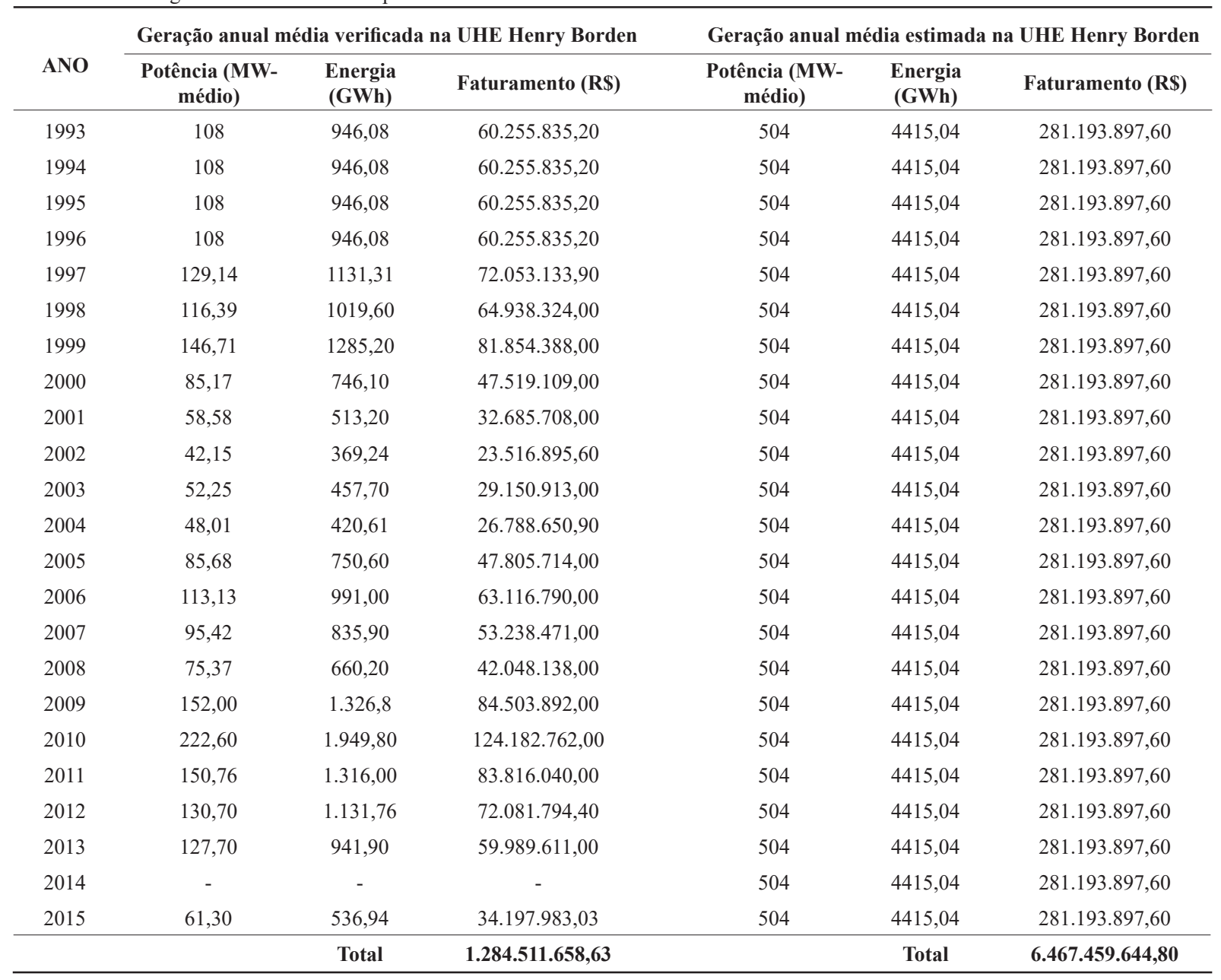

FONTE: EMAE (2009; 2010; 2011; 2012; 2013; 2015); Gramulia Jr. (2009). 
de esgotos, viabilizando a produção de água de reúso segura; a morosidade nos investimentos para a despoluição dos rios Tietê e Pinheiros; os custos de sistemas de reúso atualmente para a RMSP serem atualmente mais econômicos do que efetuar obras para importação de água, devido ao distanciamento das bacias favoráveis a essa operação.

Dessa forma, este trabalho analisou no Cenário 3 a alternativa de recarga do Reservatório com o emprego do reúso da água, que, quando aplicada, permitirá a utilização de água disponível na região e auxiliará na melhoria do desempenho do Reservatório para atender suas demandas hídricas, além de também favorecer a possibilidade de redução da demanda sobre os mananciais. Desse modo é importante salientar a necessidade de investimentos no tratamento dos esgotos na RMSP, pois eles passariam a ter um papel fundamental no planejamento e na gestão sustentável dos recursos hídricos como uma fonte de abastecimento do Reservatório.

O reúso das águas colaborará na conservação dos recursos hídricos, permitirá auxiliar o sistema Reservatório nos períodos de escassez hídrica e acrescentará uma dimensão econômica ao planejamento dos recursos hídricos, principalmente para a RMSP, que tende a aumentar sua demanda por abastecimento. Dessa forma, a recarga gerenciada, desde que possua viabilidade técnica e econômica, implicará em significativos benefícios ambientais e sociais, seja pelo acréscimo de oferta de água para o Reservatório, seja pelo aumento dos volumes de coleta e tratamento dos efluentes líquidos, reduzindo seus lançamentos nos corpos d'água de modo in natura.

Com base na discussão apresentada, percebe-se a importância e a necessidade dos setores de saneamento e de eletricidade se articularem em prol do melhor desempenho do Reservatório a fim de ter suas demandas atendidas. Cabe ressaltar que esses setores, em conjunto com a sociedade, devem juntos determinar iniciativas de planejamento e fiscalização da correta utilização do Reservatório Billings, não só nos limites municipais, mas no da bacia hidrográfica como um todo. Destaca-se ainda a importância do desenvolvimento de estudos de viabildiade técnica e econômica que indiquem soluções de tratamento de água com a aplicação do reúso potável indireto planejado, de modo a viabilizar a transferência de águas do Tietê-Pinheiros a fim de melhorar o aporte de águas na Região Metropolitana de São Paulo.

\section{Conclusão}

Com base nos resultados obtidos sobre o desempenho do Reservatório Billings em diferentes cenários de operação, pode-se concluir que o planejamento de um sistema de Reservatório é um fator essencial para que ele possa satisfazer as múltiplas demandas e que, como uma solução parcial que visa aumentar o aporte de água na Billings, a inserção da prática do reúso da água é um conceito importante a ser considerado, pois poderia auxiliar na alimentação hídrica do Reservatório até que a transferência de águas dos rios Tietê e Pinheiros volte a ser viável, como foi projetado inicialmente.

O reúso de água permitirá maior conservação dos recursos hídricos, redução da poluição dos corpos hídricos e indução à melhoria do saneamento, com medidas como a promoção do aumento da coleta e tratamento dos efluentes líquidos. Esse método auxiliará na melhoria do desempenho do Reservatório, principalmente no que tange à susten- 
tabilidade hídrica ao atender as demandas de usos múltiplos na Região Metropolitana de São Paulo, ainda que, como foi visto no Cenário 3 , não seja suficiente para atender plenamente as demandas de água na Billings, mesmo utilizando toda a vazão de água coletada do esgoto da RMSP.

Para que o reúso da água seja viável e aplicado na RMSP, será necessária a elaboração de normas para sua regulamentação e a determinação de parâmetros de análise para garantir a qualidade da água de reúso. E para que a transferência de águas retorne a operar, e passe a operar concomitantemente ao reúso de água, é importante que haja articulação entre os órgãos que regem os recursos hídricos, nas esferas federal, estadual e municipal, e seus respectivos comitês de bacias, a fim de elaborarem políticas públicas integradas e complementares à Política Nacional de Recursos Hídricos, em busca de alternativas que integrem o reúso da água e a transferência como práticas cujo objetivo vise principalmente auxiliar os reservatórios que possuem usos múltiplos.

Nesse sentido, espera-se que os resultados obtidos possam contribuir na identificação de alternativas de projetos ou de políticas preferencias de usos da água, uma vez que o planejamento integrado de recursos, bem como o gerenciamento dos usos múltiplos, é uma condição essencial para a manutenção do bem-estar social, econômico e da qualidade de vida da população.

Por fim, destaca-se que é de extrema importância analisar todos os impactos aos quais o sistema pode estar sujeito quando se busca um incremento da demanda hídrica, assim como verificar as condições operativas do Reservatório. E ressalte-se que a realização de um planejamento integrado de recursos hídricos necessita da participação de todos os agentes envolvidos em prol da promoção do plano estratégico que vise a sustentabilidade de um recurso fundamental como a água.

\section{Referências}

ANA - Agência Nacional de Águas. ATLAS Brasil - Abastecimento Urbano de Água. Brasília: ANA, 2010.

ANA - Agência Nacional de Águas. ATLAS Brasil - Abastecimento Urbano de Água: Região Metropolitana de São Paulo - 2017. Disponível em: http://atlas.ana.gov.br/Atlas/ forms/analise/RegiaoMetropolitana.asp $x$ ? $r m e=24$

ANEEL - Agência Nacional de Energia Elétrica. Banco de Informações de Geração - capacidade de geração do Brasil-janeiro de 2017. Disponível em: http://www2.aneel. gov.br/aplicacoes/capacidadebrasil/capacidadebrasil.cfm

CBH-AT - Comitê da Bacia Hidrográfica do Alto Tietê. Deliberação $C B H-A T n^{\circ} 26$ de 28 de junho de 2016. Disponível em: http://www.sigrh.sp.gov.br/public/uploads/ deliberation//CBH-AT/10702/deliberacao-cbh-at-26-de-28-06-2016-aprova-manifestaca-sobre-a-renovacao-da-outorga-do-sistema-cantareira-em-2016.pdf

CCEE - Câmara de Comercialização de Energia Elétrica. Deck de Preços-Newave-dezembro 2016. Disponível em: http://www.ccee.org.br/portal/faces/acesso_rapido_footer/ biblioteca_virtual?_adf.ctrl-state $=9$ wl2jlwil_ $4 \&_{-}{ }^{-}$afrLoop $=383687181667118$

Côrtes, P. L.; Torrente, M.; Pinto, A. P. A.; Ruiz, M. S.; Dias, A. J. G.; Rodrigues, R. Crise de abastecimento de água em São Paulo e falta de planejamento estratégico. Estudos Avançados, 29(84), 7-26, 2015. doi: 10.1590/ S0103-40142015000200002

DAEE - Departamento de Águas e Energia Elétrica. Plano Diretor de Aproveitamento dos Recursos Hídricos para a Macrometrópole Paulista - 2013. Disponível em: http:// www.daee.sp.gov.br/index.php?option=com_content\&view $=$ article \&id=1112:plano-diretor-de-aproveitamento-dos-recursos-hidricos-para-a-macrometropole-paulista

EMAE - Empresa Metropolitana de Águas e Energia S.A. 
Sistema Hidráulico da Emae - 2016a. Disponível em: http:// www.emae.com.br/usina_elevatoria_traicao.htm

EMAE - Empresa Metropolitana de Águas e Energia S.A. Usina Hidroelétrica Henry Borden - 2016b. Disponível em: http://emae.com.br/conteudo.asp?id=Usina-Hidroeletrica-Henry-Borden

EPE - Empresa de Pesquisa Energética. Plano Nacional de Energia - 2030 - ano base 2008. Disponível em: http:// www.epe.gov.br/PNE/20080512_2.pdf

EPE - Empresa de Pesquisa Energética. Relatório de Responsabilidade Socioambiental 2009. Disponível em: http:// www.emae.com.br/arquivos/internet/Investidores/Informacoes\%20Financeiras/Informacoes\%20Anuais_Trimestrais/ Balan\%C3\%A7oEMAE2009.pdf

EPE - Empresa de Pesquisa Energética. Relatório de Responsabilidade Socioambiental 2010. Disponível em: http://empresaspublicas.imprensaoficial.com.br/balancos/ emae/emae2011.pdf

EPE - Empresa de Pesquisa Energética. Relatório de Responsabilidade Socioambiental 2011. Disponível em: http:// www.emae.com.br/arquivos/internet/Investidores/Informacoes\%20Financeiras/Informacoes\%20Anuais_Trimestrais/ Balan\%C3\%A7o\%20EMAE\%202011.pdf

EPE - Empresa de Pesquisa Energética. Relatório de Responsabilidade Socioambiental 2012. Disponível em: http://www.emae.com.br/ri/relatorio_sustentabilidade/ Relatorio\%20GRI\%202012_2013.pdf

EPE - Empresa de Pesquisa Energética. Relatório de Responsabilidade Socioambiental 2013. Disponível em: http://www.emae.com.br/ri/relatorio_sustentabilidade/ Relatorio\%20GRI\%202013_2014.pdf

EPE - Empresa de Pesquisa Energética. Relatório de Responsabilidade Socioambiental 2015. Disponível em: http://www.emae.com.br/ri/relatorio_sustentabilidade/ Relatorio\%20GRI\%202015.pdf

EPE - Empresa de Pesquisa Energética. Balanço Energético Nacional 2016: ano base 2015. Rio de Janeiro, 2016. Disponível em: https://ben.epe.gov.br/BENRelatorioSintese. aspx?anoColeta $=2016 \&$ anoFimColeta $=2015$

Fonseca, A. F. Disponibilidade de nitrogênio, alterações nas características químicas do solo e do milho pela aplicação de efluente de esgoto tratado. Dissertação (Mestrado em Agricultura) - USP, 2001.

FUSP - Fundação de Apoio à Universidade de São Paulo. Plano da Bacia Hidrográfica do Alto Tietê: Relatório Final - Volume 1/4 - dezembro de 2009. Disponível em: http:// www.fabhat.org.br/site/images/docs/volume_1_pat_dez09. pdf

Gramulia Jr., J. Uma abordagem baseada em algoritmos genéticos para gerenciamento e controle de transferência não natural de água entre rios em contribuição ao planejamento da operação de sistemas hidrotérmicos. Tese (Doutorado em Energia) - UFABC, 2014.

Gramulia Jr., J. Contribuição da Usina Hidroelétrica de Henry Borden para o Planejamento da Operação de Sistemas Hidrotérmicos de Potência. Dissertação (Mestrado em Energia) - UFABC, 2009.

Hashimoto, T.; Stedinger, J. R.; Loucks, D. P. Reliability, resiliency, and vulnerability criteria for water resource system performance evaluation. Water Resources Research, 18(1), 14-20, 1982. doi: 10.1029/WR018i001p00014

Hespanhol, I. A inexorabilidade do reúso potável direto. Revista DAE, 63, 63-82, 2015. doi: 10.4322/dae.2014.141

Hespanhol, I.; Bezerril Jr., P. Conservação e reúso de água como instrumentos de gestão. Um plano diretor de reúso de água para a Região Metropolitana de São Paulo. 2008. Disponível em: http://www.brasilengenharia.com/portal/ images/stories/revistas/edicao586/ Art.Saneamento.pdf

Lira, W. S.; Cândido, G. A. Gestão sustentável dos recursos naturais: uma abordagem participativa. SciELO-EDUEPB, 2013. doi: $10.7476 / 9788578792824$

Little, P. E. Políticas ambientais no Brasil: análises, instrumentos e experiências. Editora Peirópolis, 2003.

Loucks, D. P. Quantifying trends in system sustainability. Hydrological Sciences Journal, 42(4), 513-530, 1997. doi:10.1080/02626669709492051

MCid - Ministério das Cidades. Sistema Nacional de Informações sobre o Saneamento (SNIS) - Diagnóstico dos Serviços de Água e Esgotos - ano 2015. Disponível em: http://www.snis.gov.br/diagnostico-agua-e-esgotos/ 
diagnostico-ae-2015

McMahon, T. A.; Adeloye, A. J.; Zhou, S-L. Understanding performance measures of reservoirs. Journal of Hydrology, 324(1), 359-382, 2006. doi: 10.1016/j.jhydrol.2005.09.03

Mendes, L. A. O Impacto dos usos consuntivos na operação de sistemas de reservatórios para produção de energia elétrica. 2012. Tese (Doutorado em Engenharia Hidráulica) - USP, 2012.

ONS - Operador Nacional do Sistema Elétrico. Séries Históricas de Vazões - ano base 2016. Disponível em: http:// www.ons.etc.br/operacao/vazoes_naturais.aspx

PROAM - Instituto Brasileiro de Proteção Ambiental. BILLINGS 84 anos: Impactos Ambientais. São Paulo: PROAM, 2009.

SABESP - Companhia de Saneamento Básico do Estado de São Paulo. Proposta de Renovação de Outorga do Sistema Cantareira - 30/07/2015a. Disponível em: http://www2. ana.gov.br/Paginas/servicos/outorgaefiscalizacao/renovacaocantareira.asp

SABESP - Companhia de Saneamento Básico do Estado de São Paulo. CHESS - Crise Hídrica, estratégia e soluções da SABESP para a Região Metropolitana de São Paulo30/04/2015b. Disponível em: http://site.sabesp.com.br/site/ uploads/file/crisehidrica/chess_crise_hidrica.pdf

SABESP - Companhia de Saneamento Básico do Estado de São Paulo. DOSSIE Sistema Rio Grande - 2009. Disponível em: http://memoriasabesp.sabesp.com.br/acervos/dossies/ pdf/7_dossie_sistema_rio_grande.pdf6
São Paulo. Prefeitura Municipal de São Paulo. Elaboração do Plano de Desenvolvimento e Proteção Ambiental da Bacia Hidrográfica do Reservatório Billings. São Paulo, SP, 2010.

São Paulo. Prefeitura Municipal de São Paulo.Plano estadual de recursos hídricos: PERH 2012-2015: relatório de acompanhamento: ano 2012 / Governo do Estado de São Paulo, Secretaria de Saneamento e Recursos Hidricos, Coordenadoria de Recursos Hídricos. 1. ed. São Paulo: Coordenadoria de Recursos Hídricos, 2014.

São Paulo. Prefeitura Municipal de São Paulo.Resolução Conjunta SMA / SSE no. 3, de 04 de setembro de 1992. Trata de procedimentos a serem adotados em casos de emergência na operação do sistema hídrico da bacia do Alto Tietê e bacias a ela interligadas. Diário Oficial do Estado de São Paulo. SP, 04 set. 1992.

São Paulo. Prefeitura Municipal de São Paulo.Resolução Conjunta SMA / SSE-002, de 19 de fevereiro de 2010. Trata de procedimentos a serem adotados em casos de emergência na operação do sistema hídrico da bacia do Alto Tietê e bacias a ela interligadas. Diário Oficial do Estado de São Paulo. SP, 19 fev. 2010. Seção 1, p. 112.

Silva, J. M. B. Abordagem dinâmica e hidroenergética como alternativa de recomposição de carga a partir da usina hidroelétrica Henry Borden. Dissertação (Mestrado em Energia) - UFABC, 2016.

Tosetto, M. S. Tratamento terciário de esgoto sanitário para fins de reúso urbano. Dissertação (Mestrado em Engenharia Civil) - UNICAMP, 2005. 